\title{
FORMAÇÕES IMAGINÁRIAS DE PROFESSORES DOS ANOS INICIAIS DO ENSINO FUNDAMENTAL SOBRE A FORMA DA TERRA E O CONCEITO DE GRAVIDADE
}

\author{
SORANDRA CORRÊA DE LIMA' * \\ https://orcid.org/0000-0002-8158-0136 \\ ROBERTO NARDI" * * \\ https://orcid.org/0000-0002-5018-3621
}

RESUMO Este artigo analisa discursos de professoras dos anos iniciais do ensino fundamental sobre o planeta Terra e o conceito de gravidade. Os dados foram constituídos durante um curso realizado em serviço, em uma escola pública urbana do interior do estado de Minas Gerais, Brasil, com assessoria de pesquisadores da Universidade. Destacamos aqui as formações imaginárias das docentes, presentes em repostas e questionários, desenhos elaborados sobre o tema e reuniões de reflexão realizadas durante o projeto e interpretadas utilizando noções de Análise de Discurso estabelecidas por Pêcheux e Orlandi. A pesquisa mostra que o fato de as atividades ocorrerem em serviço e em cooperação com a universidade gerou diferenças em relação a projetos anteriores. Mostra, ainda, que as atividades baseadas em resultados de pesquisa anteriores, assim como as experiências das participantes do grupo, oportunizaram discussões sobre o planeta Terra e o conceito de gravidade, caminhando para a visão científica. Palavras-chave: Ensino de Ciências. Anos Iniciais do Ensino Fundamental. Formação Continuada.

FORMACIONES IMAGINARIAS DE PROFESORES DE LOS PRIMEROS AÑOS DE LA EDUCACIÓN PRIMARIA SOBRE LA FORMA DE LA TIERRA Y EL CONCEPTO DE GRAVEDAD

RESUMEN: Este artículo analiza los discursos de profesoras de los primeros años de la educación primaria acerca del planeta Tierra y del concepto de gravedad. Los datos se constituyeron durante un curso realizado en servicio, en una escuela pública urbana en el interior del estado de Minas Gerais, Brasil, con el auxilio de investigadores de la

*Doutora em Educação para
Ciência pela Universidade Estadual
Paulista “Júlio de Mesquita Filho"
(UNESP) campus Bauru. Professora
efetiva no Instituto de Física,
na Universidade Federal de
Uberlândia (UFU) e integrante
do Grupo de Pesquisa em
Ensino de Ciências, Programa
Pós-Graduação em Educação
para Ciência (UNESP).
E-mail: sorandra@ufu.br
**Doutor em Educação pela
Faculdade de Educação da
Universidade de São Paulo, FEUSP.
Professor no Departamento de
Educação e no Programa de
Pós-graduação em Educação para a
Ciência da Faculdade de Ciências
da UNESP, Bauru. Bolsista de
Produtividade em Pesquisa
1-A do CNPq e um dos líderes
do Grupo de Pesquisa em Ensino
de Ciências, Programa de
Pós-Graduaçaao em Educação
para a Ciência (UNESP).
e-mail: r.nardi@unesp.br

I Universidade Federal de Uberlândia, Instituto de Física, Uberlândia, MG - Brasil.

II Universidade Estadual Paulista, Faculdade de Ciências, Programa de Pós-graduação em Educação para a Ciência, Bauru, SP - Brasil 
Universidad. Destacamos aquí las formaciones imaginarias de las profesoras, que constan en las respuestas y los cuestionarios, en los dibujos elaborados sobre el tema y reuniones de reflexión ocurridas durante el proyecto e interpretadas por medio de las nociones del Análisis del Discurso establecidas por Pêcheux y Orlandi. La investigación muestra que el hecho de que las actividades se realicen en el servicio y en cooperación con la universidad marcó una diferencia en relación con los proyectos anteriores. También demuestra que las actividades basadas en los resultados de investigaciones anteriores, así como las experiencias de las participantes del grupo, permitieron discusiones sobre el planeta Tierra y el concepto de gravedad, avanzando hacia una visión científica.

Palabras clave: Enseñanza de las Ciencias. Primeros Años de la Educación Primaria. Formación Continua.

\section{IMAGINARY FORMATIONS OF TEACHERS FROM THE EARLIEST YEARS OF ELEMENTARY SCHOOL ON THE FORM OF EARTH AND THE CONCEPT OF GRAVITY}

ABSTRACT: This article analyzes speeches of teachers from the early years of elementary school about the planet Earth and the concept of gravity. The data were collected during a course held in service, in an urban public school in the interior of the state of Minas Gerais, Brazil, with the assistance of researchers from the University. We highlight the teachers' imaginary formations, present in answers and questionnaires, drawings elaborated on the theme and reflection meetings held during the project and interpreted using notions of Discourse Analysis established by Pêcheux and Orlandi. The research shows that the fact that the activities took place in service and in cooperation with the university made a difference compared to previous projects. It also shows that the activities based on previous research results, as well as the experiences of the participants of the groups, enabled discussions about the planet Earth and the concepts of gravity, moving towards the scientific view.

Keywords: Science teaching. Initial years of Elementary School. Continuing education 


\section{INTRODUÇÃO}

Este artigo descreve parte de uma pesquisa de doutorado, cujos dados foram constituídos durante o desenvolvimento de um projeto de parceria universidade-escola pública, realizado em uma unidade escolar do interior do estado de Minas Gerais, Brasil. No projeto, pesquisadores da universidade buscaram assessorar professoras atuando no primeiro e segundo ciclos dos anos iniciais do ensino fundamental, em assuntos relacionados ao ensino de Ciências, particularmente de Física.

Tendo como base documentos emanados do Ministério da Educação, os estados brasileiros, por meio de suas secretarias de Educação, e em parceria com diversos órgãos, inclusive universidades, organizam seus currículos, com orientações teóricas e metodológicas para a educação básica. Em Minas Gerias, o documento com esta finalidade recebeu o nome de Currículo Básico Comum (CBC). ${ }^{1}$ Neste documento, o ensino de Ciências dos anos iniciais está organizado em quatro eixos: 1: Ambiente e Vida; 2: Corpo humano e Saúde; 3: Terra e Universo; e, 4: Tecnologia e Sociedade.

Desde o início do projeto, em contatos para estabelecimento da parceria, os pesquisadores, autores deste artigo, perceberam que a maioria das professoras, atuantes nesta unidade escolar, citava o CBC como referência para elaboração de seus planos de ensino. Especificamente no caso do ensino de Ciências, as docentes, a maior parte com formação em Pedagogia, mostravam sentir dificuldades e, portanto, insegurança, em trabalhar com os eixos temáticos "Terra e Universo" e "Ciência e Tecnologia" durante suas aulas.

A insegurança mostrava-se mais aparente quando, por exemplo, eram veiculadas nas redes sociais notícias como as que procuram atribuir ao planeta Terra uma forma plana. Isto, além de despertar a curiosidade de muitos internautas, leva o assunto para as salas de aulas, quando professores de Ciências e Física são acionados por seus alunos (LANG, 2017).

Neste artigo, destacamos uma das atividades de ensino, relacionada a esta problemática, que foi temática de uma das partes do projeto acima citado. O objetivo deste artigo é evidenciar os gestos de interpretação e as formações imaginárias das professoras, quando questionadas sobre a forma do planeta Terra e o conceito de gravidade. Esses dados foram constituídos analisando discursos e desenhos das docentes, obtidos por meio de uma atividade inspirada no artigo de Nardi e Carvalho (1996).

Sobre a temática, ressaltamos a seguir algumas pesquisas relacionadas ao assunto, buscando apoio na literatura da área de ensino de Física/Ciências, uma vez que o grupo de pesquisa, ao qual pertencem os pesquisadores, autores deste texto, tem como um dos focos principais promover parcerias entre a universidade e as escolas, que promovam "o diálogo entre a produção acadêmica em Ensino de Ciências e os saberes e práticas docentes em diferentes níveis de ensino e espaços educativos" (NARDI et al., 2016). 


\section{ALGUMAS PESQUISAS SOBRE O TEMA FORMA DA TERRA E O CONCEITO GRAVIDADE EM CURSOS DE FORMAÇÃO DE PROFESSORES}

Com o propósito de estabelecer vínculos entre as atividades desenvolvidas no projeto e a literatura em Educação em Ciências, os pesquisadores realizaram um amplo levantamento de artigos publicados recentemente em periódicos nacionais, já consolidados na área. Especificamente para o tema desta atividade, foram selecionados os seguintes periódicos: Revista Latino-Americana de Educação em Astronomia (RELEA); Caderno Brasileiro de Ensino de Física; Ciência \& Educação; Ensaio - Pesquisa em Educação em Ciências, Revista Brasileira de Pesquisa em Educaşão em Ciências (RBPEC) e Investigações em Ensino de Ciências.

O critério de busca consistiu primeiramente na seleção de artigos pelas seguintes palavras-chave: forma da Terra e gravidade. Em seguida, foram analisados os artigos, visando localizar o vínculo da temática com a formação docente. Foram encontrados três artigos com este perfil, que são descritos a seguir.

Pinto, Fonseca e Vianna (2007) relatam as estratégias utilizadas em um curso de curta duração em Astronomia básica, destinado a professores do primeiro segmento do ensino fundamental. Os autores destacam, conforme a Figura 1, as concepções dos professores sobre o planeta Terra e o posicionamento dos seres humanos no planeta. As respostas apresentadas pelos professores foram categorizadas de acordo com os desenhos apresentados na figura.

Figura 1. Modelos de Terra e do posicionamento do ser humano sobre o planeta Terra, segundo a pesquisa de Pinto, Fonseca e Vianna (2007)

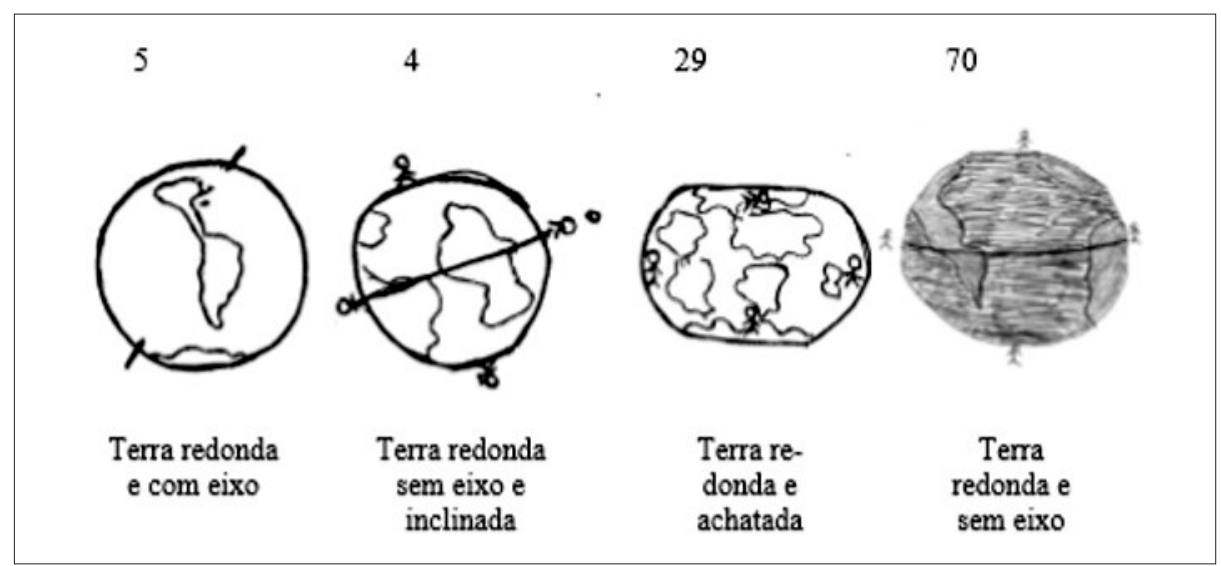

Observação: Os números acima de cada desenho correspondem à ocorrência dos modelos.

Fonte: Pinto, Fonseca e Vianna (2007, p. 77).

$\mathrm{O}$ artigo mostra que nenhum professor teve dúvida sobre a esfericidade da Terra. Alguns enriqueceram seus desenhos com detalhes, tais como: eixo inclinado, linha do Equador, oceanos etc. Quando os docentes, entretanto, foram questionados sobre quais argumentos poderiam utilizar para comprovar essa esfericidade, não conseguiram responder de forma satisfatória e coerente. 
Leite e Hosoume (2007) também realizaram um estudo, com professores de Ciências do ensino fundamental, sobre elementos de Astronomia. Mapearam as concepções sobre formas e dimensões da Terra, Sol, Lua, planetas e estrelas, bem como as concepções de Céu e de Universo, como um todo. Em relação à representação do planeta Terra, os autores organizaram as concepções dos professores em três categorias de análise (vivencial, livro didático e científico). $\mathrm{Na}$ categoria vivencial, foi possível identificar três tipos de caracterização da Terra: Terra plana, Terra esférica e oca e ainda a Terra esférica, porém com vertical absoluta. $\mathrm{Na}$ categoria livro didático, estavam as respostas que representam a Terra na forma esférica, com um exagerado achatamento em seus polos. E por fim, na categoria científico, os entrevistados que escolheram a forma esférica para representar a Terra. Em suas conclusões, as autoras apontam que "surpreendente é a extrema semelhança das concepções dos professores com as dos alunos ou crianças" (LEITE; HOSOUME, 2007, p. 64). Essas conclusões, mais uma vez, ratificamos dados encontrados pelos autores anteriormente citados.

O artigo de Ferreira e Leite (2015), por sua vez, mostra resultados de investigação sobre as percepções de professores acerca das relações entre o conhecimento oriundo da observação e os modelos científicos atualmente aceitos sobre os temas "forma e movimentos da Terra". Os dados analisados foram constituídos a partir de respostas dadas em uma proposta didática realizada em um curso de extensão universitária para formação continuada de professores, e estruturada a partir da dinâmica dos Três Momentos Pedagógicos e guiada por algumas das ideias centrais de Paulo Freire. Os autores categorizaram as percepções dos professores da seguinte forma: 1) Compreende as relações e as explica, quando demonstraram perceber que há uma aparente contradição entre o que se observa e o modelo científico atualmente aceito para a forma da Terra. 2) Compreende as relações e não as explica, quando também perceberam a contradição aparente e, no entanto, seus argumentos não explicaram o porquê dessa contradição ocorrer. 3)Não compreende as relações, quando o participante não mostrou perceber que a observação cotidiana não nos possibilita concluir diretamente que a Terra possui movimento de revolução.

Os estudos acima mostram a importância, portanto, de se incluir o tema na formação continuada de docentes de educação básica. Torna-se ainda mais importante, uma vez que evidenciam a ineficácia do livro didático (alguns, até com a presença de erros conceituais) e dos meios de comunicação em geral que, por exemplo, apesar de apresentarem uma Terra esférica, não fazem uma associação desta forma com a que observamos em nosso cotidiano. Além disso, os resultados das pesquisas acima referem-se à tomada de dados em curso de curta duração; em nosso caso, as atividades foram realizadas na unidade escolar, tiveram duração de cerca de um ano e, também, a assessoria de pesquisadores da universidade. $\mathrm{O}$ fato de se levar em consideração as demandas das professoras, bem como ser realizado em serviço, mostram-se um diferencial nesta pesquisa, constituindo-se, segundo os participantes do projeto, como uma inovação (LIMA, 2018).

Este estudo tem a Análise de Discurso como referencial teóricometodológico. Neste sentido, o diálogo com os resultados de outras pesquisas, como as acima citadas, embora desenvolvidas em diferentes contextos de produção, foram importantes para a análise dos dados constituídos em nossa pesquisa. 


\section{REFERENCIAL TEÓRICO-METODOLÓGICO: ANÁLISE DE DISCURSO DE FILIAC̣ÃO FRANCESA}

Falas, respostas a questionários e entrevistas de professores participantes do projeto foram analisados na perspectiva da Análise de Discurso de linha francesa (AD), referenciados principalmente em Pêcheux (1989) e Orlandi (1995).

Nesta linha de AD, Pêcheux considera do Materialismo Histórico o conceito de Althusser, segundo o qual, os sujeitos são interpelados pela ideologia e determinados historicamente.

O discurso é assim palavra em movimento, prática de linguagem: com o estudo do discurso observa-se o homem falando. $\mathrm{Na}$ análise de Discurso, procura-se compreender a língua fazendo sentido, enquanto trabalho simbólico, parte do trabalho social geral, constitutivo do homem e da sua história (ORLANDI, 2013, p. 15).

Assim, o discurso é uma prática ideológica, que não é um mascaramento, mas uma evidência de sentido. As formações discursivas são materializadas por meio de nossas palavras, que possuem sentidos diferentes para sujeitos diferentes, pois são interpelados de forma distinta pelas ideologias com as quais se identificam. Podemos dizer que a formação discursiva será como um filtro para os dizeres do sujeito, enquanto o interdiscurso proporciona várias interpretações possíveis. Dessa forma, é a Formação Discursiva que determina os limites dessas possibilidades, circunscrevendo ao sujeito as possibilidades de sentidos que condizem com as ideologias e os discursos por ele seguidos e que cabem no determinado contexto em que se encontra (SANTOS, 2016).

Para a Análise de Discurso francesa, "inconsciente" e "ideologia" são de ordens distintas, mas encontram-se materialmente ligados na ordem significante da língua. Dessa maneira, Pêcheux (1990) tinha em mente os seguintes objetivos da Análise de Discurso: compreender o funcionamento do discurso como sendo efeitos de sentidos, analisar os discursos e observar como os sentidos produzem as interpelações.

Segundo Orlandi (2005):

Merece atenção o fato de que a análise de discurso se constitui na conjuntura intelectual do estruturalismo do final dos anos 60 , em que a grande questão é a relação da estrutura com a história, do indivíduo com o sujeito, da língua com a fala, assim como se interroga a interpretação. Tomo em conta que a passagem que se faz é justamente a passagem que coloca em questão as noções de sujeito, de indivíduo, de língua, de fala, de história e de interpretação, então vigentes, assim como se procura ultrapassar as dicotomias estabelecidas e pôr em questão a suposta transparência do sentido. Para isto a análise de discurso reúne, deslocando, língua-sujeito-história, construindo um objeto próprio, o discurso, e um campo teórico específico (ORLANDI, 2005, p. 6).

Pela psicanálise, somos falados pelo inconsciente e pela Análise de Discurso, somos falados pela ideologia. Segundo Orlandi (2005) podemos dizer que ideologia é o imaginário que nos relaciona com as nossas condições de existência. Não significa ocultação da maneira que se pensa, pois, a própria interpretação nos 
mostra a posição ideológica e quando uma pessoa interpreta de uma forma e outra pessoa de outra, fica explícita a ideologia (ORLANDI, 2005).

Assim, podemos relacionar dois termos que estão atrelados ao conceito de ideologia: o de formação ideológica e o de formação discursiva. Pêcheux e Fuchs (1997, p. 167 apud BARROS, 2015) exemplificam:

[...] a formação ideológica religiosa constitui, no modo de produção feudal, a forma da ideologia dominante; ela realiza "a interpelação dos indivíduos em sujeitos" através do aparelho ideológico do Estado religioso "especializado" nas relações de Deus com os homens, sujeitos de Deus, na forma específica das cerimônias (ofícios, batismos, casamentos, enterros etc.) que, sob a figura da religião, intervém, em realidade, nas relações jurídicas e na produção econômica, portanto no próprio interior das relações de produção feudais. Na realização dessas relações ideológicas de classes, diversas formações discursivas intervêm enquanto componentes combinadas cada vez em formas específicas; por exemplo, e enquanto hipótese histórica a ser verificada: de um lado a pregação camponesa reproduzida pelo "baixo clero" no interior do campesinato, de outro o sermão do alto clero para os grandes da nobreza, logo duas formações discursivas [...] (BARROS, 2015, p. 85).

Segundo Barros (2015), esse exemplo esclarece bem a conceituação de ideologia, enquanto formação ideológica no interior da teoria do discurso, uma vez que "existe, no exemplo, uma única formação ideológica, a qual permeia outros dois exemplos de formação discursiva, mas que, dada a conjuntura apresentada, pode conter um número bem maior delas" (BARROS, 2015, p. 84).

Segundo a Análise de Discurso (AD), é imprescindível deixar claro em qual contexto as enunciações se materializam, em que posição e local surgiram os enunciados. Nessa perspectiva, Orlandi (2008) afirma que a produção de discurso se faz articulando dois processos: o parafrásico e o polissêmico. Para a autora "o processo parafrásico é o que permite a produção do mesmo sentido, sob as várias de suas formas (matriz da linguagem). "O processo polissêmico é o responsável pelo fato de que são sempre possíveis sentidos diferentes, múltiplos (fonte da linguagem)." (ORLANDI, 2008, p. 20). A autora sustenta que o funcionamento da linguagem acontece sobre a tensão entre paráfrase (repetição) e a polissemia (diferença).

Assim, “[...] o que funciona entre o mesmo e o diferente é o imaginário na constituição dos sentidos, é a historicidade na formação da memória”. O mesmo seria caracterizado como um retorno ao espaço dizível (paráfrase), porém com variedade da situação e dos locutores. Já o diferente, nas mesmas condições imediatas (locutores e situação) há um deslocamento de sentidos (polissemia) (ORLANDI, 1998, p. 15).

$\mathrm{Na}$ tensão entre esses processos, os movimentos podem ser contrários, contraditórios, divergentes, partindo em diferentes direções, produzindo o que chamamos "sentidos em fuga", no efeito do silenciamento, no funcionamento do interdiscurso (da memória), por causa da ideologia.

Já as formações imaginárias do sujeito do discurso, são constituídas de: o modo como se fala; o modo como suas palavras produzem certos sentidos e não outros; e o modo como é visto e como se vê, que estão vinculados a certas 
posições ideológicas (GIRALDI, 2010). Conforme esta definição, Orlandi (1996) estabelece três mecanismos imaginários de funcionamento do discurso:

Falar em discurso é falar em condições de produção e, em relação a essas condições gostaríamos de destacar que, como exposto por Pêcheux (1979), são formações imaginárias, e nessas formações contam a relação de forças (os lugares sociais dos interlocutores e sua posição relativa no discurso), a relação de sentido (o coro de vozes, a intertextualidade, a relação que existe entre um discurso e outros) e a antecipação (a maneira como o locutor representa as representações de seus interlocutores e vice-versa) (ORLANDI, 1996, p. 158, grifos nossos).

Esses mecanismos de funcionamento do discurso (relações de sentidos, relações de força e antecipação) constituem as formações imaginárias que, para Pêcheux (1990), designam o lugar que A e B se atribuem cada um a si e ao outro e a imagem que eles fazem de seu próprio lugar e do lugar do outro. Com isso, de acordo com Orlandi (2009), não são os sujeitos físicos nem os seus lugares empíricos, como estão inscritos na sociedade, e que poderiam ser sociologicamente descritos, que funcionam no discurso, mas suas imagens que resultam de projeções.

Para explicitar isso de forma mais clara, Pêcheux (1997) organizou um quadro, no qual ilustra que todo processo discursivo supõe a existência de formações imaginárias (Quadro 1).

Quadro 1. Formações imaginárias.

\begin{tabular}{|c|l|l|}
\hline $\begin{array}{c}\text { Expressão } \\
\text { que designa } \\
\text { as formações } \\
\text { imaginárias }\end{array}$ & Significação da expressão & $\begin{array}{c}\text { Questão implícita cuja } \\
\text { "resposta" subentende } \\
\text { a formação imaginária } \\
\text { correspondente }\end{array}$ \\
\hline IA(A) & $\begin{array}{c}\text { Imagem do lugar de A para } \\
\text { o sujeito colocado em A }\end{array}$ & $\begin{array}{c}\text { Quem sou eu para lhe falar } \\
\text { assim? }\end{array}$ \\
\hline IA(B) & $\begin{array}{l}\text { Imagem do lugar de B para } \\
\text { o sujeito colocado em A }\end{array}$ & $\begin{array}{l}\text { Quem é ele para que eu lhe } \\
\text { fale assim? }\end{array}$ \\
\hline IB(B) & $\begin{array}{l}\text { Imagem do lugar de B para } \\
\text { o sujeito colocado em B }\end{array}$ & $\begin{array}{l}\text { Quem sou eu para que ele } \\
\text { me fale assim? }\end{array}$ \\
\hline IB(A) & $\begin{array}{l}\text { Imagem do lugar de A para } \\
\text { o sujeito colocado em B }\end{array}$ & $\begin{array}{l}\text { Quem é ele para que me } \\
\text { fale assim? }\end{array}$ \\
\hline
\end{tabular}

Fonte: Pêcheux (1997).

Esse esquema se referia ao "lugar" ou "posição" social de quem fala, em que acredita que se situa e que o outro se situa, assim como uma antecipação daquilo que o outro pensa acerca do próprio lugar e do lugar do interlocutor.

Segundo Pêcheux (1990), em um discurso está presente o sujeito A e destinatário $\mathrm{B}$, que se encontram em lugares determinados na estrutura de uma formação social. Estes lugares se acham não apenas representados nos processos 
discursivos, mas são transformados. A partir disso, um discurso não implica necessariamente em uma mera troca de informações entre A e B, mas sim um jogo de "efeitos de sentido" entre os participantes. Os sentidos seriam produzidos por certo imaginário, que é social e é, por sua vez, resultado das relações entre poder e sentidos.

Neste artigo, procuramos interpretar as formações imaginárias de professoras sobre a forma da Terra e gravidade, evidenciando as relações de força, sentidos e antecipação em seus discursos.

\section{METODOLOGIA E CONTEXTO DE PRODUÇÃO DA PESQUISA}

A metodologia de pesquisa utilizada obedeceu aos parâmetros da abordagem qualitativa. Segundo Gonzáles-Rey (2001), “a pesquisa qualitativa que assume os princípios da Epistemologia Qualitativa, se caracteriza pelo seu caráter construtivo-interpretativo, dialógico e pela sua atenção ao estudo de casos singulares" (GONZÁLES-REY, 2001, p. 12).

A seguir, são apresentados alguns detalhes do contexto de constituição dos dados, os instrumentos utilizados, bem como características das professoras que participaram da pesquisa.

\section{a) Contexto de constituição dos dados}

O projeto ocorreu em escola pública de zona urbana de um município de cerca de 50.000 habitantes, no interior do estado de Minas Gerais. Destaca-se que um dos autores desse projeto (primeira autora) esteve engajada nesta escola, durante a constituição dos dados, por um período de cerca de um ano.

O ambiente mostrou-se bastante favorável no acolhimento da pesquisadora, que estudou os anos iniciais de escolarização nesta mesma escola, retornando agora, como pesquisadora de uma universidade pública. A direção e a coordenação foram bastante receptivas, uma vez que, além da peculiaridade acima citada, o projeto teve a parceria da universidade, por meio de uma ação de extensão, que teve como base um curso de educação continuada, envolvendo todas as professoras que atuam na escola. Assim, o ambiente foi bastante cordial durante o desenrolar do projeto e continuou, mesmo depois do término oficial do mesmo, que se constituiu em elemento fundamental dentro do curso de formação continuada promovido.

A constituição dos dados foi baseada nas situações vividas pelas participantes durante o curso, intitulado "Atividades de Física nas Aulas de Ciências dos Anos Iniciais do Ensino Fundamental". As atividades ocorreram, em serviço, basicamente durante o Horário de Trabalho Pedagógico Coletivo (HTPC), em reuniões pedagógicas nessa escola, durante cerca de doze meses. O contexto e as condições de produção das atividades realizadas durante as reuniões pedagógicas semanais foram registrados pela pesquisadora e posteriormente transcritos para análise.

E preciso considerar cada uma das professoras participantes do projeto como portadora de uma história de vida, incluindo aí sua experiência profissional, que orienta o seu olhar e justifica determinados interesses e necessidades (CUNHA; PRADO, 2010). Esclarecemos que o projeto contou com um grupo de 22 professoras dos anos iniciais do Ensino Fundamental, em sua maioria pedagogas, 
com experiência de ensino variando entre cinco a 27 anos, que ministram também aulas de Ciências, tendo como referência o CBC do estado de Minas Gerais. Todas, com exceção de uma delas, aceitaram participar do projeto e, para tanto, assinaram o Termo de Consentimento Livre e Esclarecido (TCLE), declarando que autorizavam a utilização das transcrições das entrevistas e dos encontros coletivos, da observação de suas aulas e utilização de trechos de seus planos de aula, para fins exclusivos da pesquisa. Foi garantido que seus nomes e o da escola, bem como a identificação de suas produções individuais realizadas durante o projeto, seriam utilizados apenas para fins de pesquisa. Ressaltamos que, como o início do curso se deu no final do ano letivo, no ano seguinte houve uma grande rotatividade de professoras na escola. Isso se deve ao tipo de contratação do professor, (temporário ou efetivo) ou, como no caso de uma das professoras, que regressou à escola na etapa final do curso, devido à licença maternidade. Por esse motivo, para mantermos a coerência em nossa pesquisa, consideramos na análise das atividades desenvolvidas, como no caso deste artigo, que se refere à "atividade do astronauta", apenas as professoras que estavam presentes no dia da discussão da mesma.

Logo nos primeiros encontros ficou evidente que as professoras, a maioria com formação em Pedagogia, possuíam dificuldades para ensinar conteúdos de dois dos quatro eixos exigidos pelo documento Currículo Básico Comum (CBC) de Ciências: Terra e Universo e Ciência e Tecnologia. Assim, as atividades práticas foram selecionadas dentre os conteúdos citados nesses eixos, por solicitação das docentes. Por conta dos objetivos do projeto, as atividades experimentais foram embasadas em produções resultantes de pesquisas divulgadas em teses, dissertações e publicadas em periódicos da área de ensino de Física e/ou Ciências.

No dia de reunião pedagógica, em que foi proposta a atividade focada neste artigo, 17 professoras participaram: Leda, Luciana, Maria, Abadia, Mariana, Kelly, Rute, Eliane, Soraia, Fernanda, Paula, Andressa, Eva, Norma, Sara, Deise e Helena. Esses nomes são fictícios, criados apenas para preservar a identidade das professoras.

Nessa reunião, partiu-se da "atividade do astronauta", baseada em artigo de Nardi e Carvalho (1996), que discute o conceito de campo gravitacional e concepções alternativas relacionadas à forma da Terra. A reunião iniciou-se com a apresentação de um dispositivo (Figura 2) em que aparece um astronauta no espaço, próximo a uma nave espacial (NARDI; CARVALHO, 1996). As professoras foram questionadas com base no protocolo de entrevistas utilizado no estudo acima citado. As questões foram as seguintes: O que vocês estão vendo na figura? Onde você está neste desenho? E o astronauta, onde está? Se você soltar uma pedra de suas mãos o que acontece? Se o astronauta soltar uma pedra das mãos, o que acontece? A seguir, foi entregue uma folha de papel em branco e um lápis para todas, que foram solicitadas a elaborar um desenho de como representariam o planeta Terra. 
Figura 2. Dispositivo utilizado na atividade do astronauta

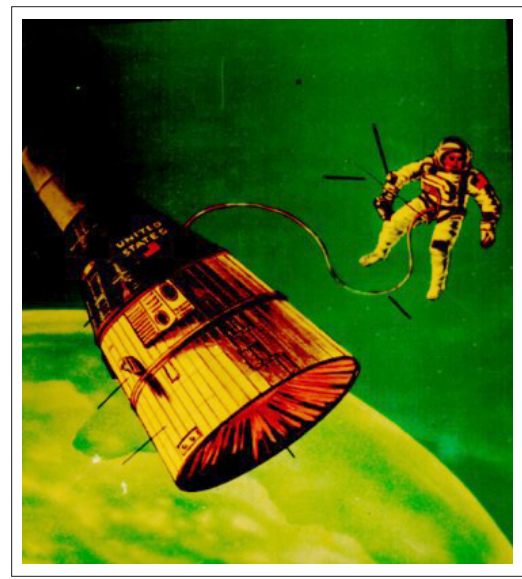

Fonte: Nardi e Carvalho (1996).

A seguir, foram projetadas as principais partes do artigo de Nardi e Carvalho (1996), no qual são detalhadas os objetivos, metodologia, análise dos dados e conclusões da pesquisa. Os resultados foram comparados com as concepções apresentadas pelas professoras. Como resultados das discussões, duas das professoras, Paula e Andressa se comprometeram a realizar a mesma experiência com seus alunos. Foram convidadas para apresentar os resultados na próxima reunião, a fim de socializá-los com as demais professoras. E assim aconteceu.

Todos os encontros promovidos durante o curso ocorreram de forma semelhante e foram registrados com uma câmera digital e transcritos literalmente, não tendo sido feitas quaisquer alterações. Adaptamos um código de transcrição (VILLANI, 2002) contendo as convenções utilizadas para registrar as falas, bem como alguns códigos utilizados por Castilho e Preti (1986).

O código de transcrição utilizado, conforme apresentado no Quadro 2, pretendeu registrar os aspectos verbais e não verbais dos discursos das professoras. Uma das vantagens que a gravação em vídeo proporciona é que as cenas registradas podem ser revistas, sempre que necessário. 
Quadro 2. Resumo explicativo das normas utilizadas para a transcrição das falas dos professores.

\begin{tabular}{|c|c|c|}
\hline Locutores & Palavras não identificadas & $\begin{array}{l}\text { Particularidades } \\
\text { discursivas }\end{array}$ \\
\hline P: Pesquisador & $\begin{array}{l}\text { * : uma ou mais } \\
\text { sílabas inaudíveis ou } \\
\text { incompreensíveis }\end{array}$ & $\begin{array}{c}\text { ! : entonação interpretada } \\
\text { como exclamativa }\end{array}$ \\
\hline $\begin{array}{c}\text { Nome: nome fictício atribuído } \\
\text { ao professor }\end{array}$ & & $\begin{array}{c}\text { ? : entonação interpretada } \\
\text { como interrogativa }\end{array}$ \\
\hline $\begin{array}{l}\text { CP: Coordenadora } \\
\text { Pedagógica }\end{array}$ & $\begin{array}{l}* * *: \text { palavras ou } \\
\text { expressões inaudíveis ou } \\
\text { incompreensíveis }\end{array}$ & $\begin{array}{l}\text { /// : pausa longa } \\
\text { (maior de } 2 \mathrm{~s} \text { ) }\end{array}$ \\
\hline Diretora & $\begin{array}{c}\text { (inaudível): grandes trechos } \\
\text { incompreensíveis do } \\
\text { discurso }\end{array}$ & $\begin{array}{l}\text { (sic): citação textualmente } \\
\text { apresentada conforme } \\
\text { a fala do professor, com } \\
\text { erro de português. }\end{array}$ \\
\hline \multirow[t]{8}{*}{ Vice-Diretora } & & Rs: risos \\
\hline & & $\begin{array}{l}\text { / : pausa breve } \\
\text { (menor de } 2 \mathrm{~s} \text { ) }\end{array}$ \\
\hline & & $\begin{array}{c}\text { (enitalique e entre } \\
\text { parênteses): um locutor } \\
\text { fala ao mesmo tempo } \\
\text { de outro locutor }\end{array}$ \\
\hline & & $\begin{array}{l}\frac{\text { [sublinhado e entre }}{\text { colchete] observações }} \\
\text { do transcritor }\end{array}$ \\
\hline & & $\begin{array}{l}\text { (?) : enunciado } \\
\text { incompreensível }\end{array}$ \\
\hline & & (): silêncio \\
\hline & & $\begin{array}{c}\text { Maiúsculas: entoação } \\
\text { enfática }\end{array}$ \\
\hline & & ... alongamento de vogal \\
\hline
\end{tabular}

Fonte: os autores. 


\section{GESTOS DE INTERPRETAC̣ÃO E FORMAC̣ÕES IMAGINÁRIAS}

\subsection{FORMATO DA TERRA E GRAVIDADE}

Quanto ao formato da Terra, os imaginários das professoras foram interpretados a partir da análise dos desenhos realizados na tarefa citada anteriormente. Os imaginários foram basicamente de dois tipos. Em um deles apresenta a Terra redonda e achatada nos polos. Este foi o caso de Luciana, Paula, Andressa, Norma, Soraia e Rute. O outro apresenta a Terra redonda e sem eixo; foi o caso das demais docentes: Deise, Kelly, Leda, Helena, Sara, Eliane, Fernanda, Abadia, Mariana, Eva e Maria.

Neste caso, como na pesquisa de Pinto, Fonseca e Vianna (2007), nenhuma professora teve dúvida sobre a esfericidade da Terra. Em nossa pesquisa, algumas enriqueceram seus desenhos com detalhes, tais como: crosta terrestre, cidades, oceanos etc. Diferentemente dos sujeitos estudados na pesquisa de Pinto, Fonseca e Vianna (2007), entretanto, nenhuma professora comentou o fato de a Terra ter um eixo ou ser inclinada.

Ressaltamos que, no momento de detalhar elementos de seus respectivos desenhos, todas as professoras consideraram a posição onde estão situadas na Terra. E todas elas, sem exceção, afirmaram que estamos na superfície do planeta. Porém, seus desenhos realçaram outros aspectos, incoerentes com suas falas. Essas representações foram categorizadas de acordo com os desenhos apresentados e suas semelhanças, conforme o Quadro3. 
Quadro 3. Formações imaginárias das professoras quanto à forma da Terra e seu respectivo posicionamento na superfície da Terra

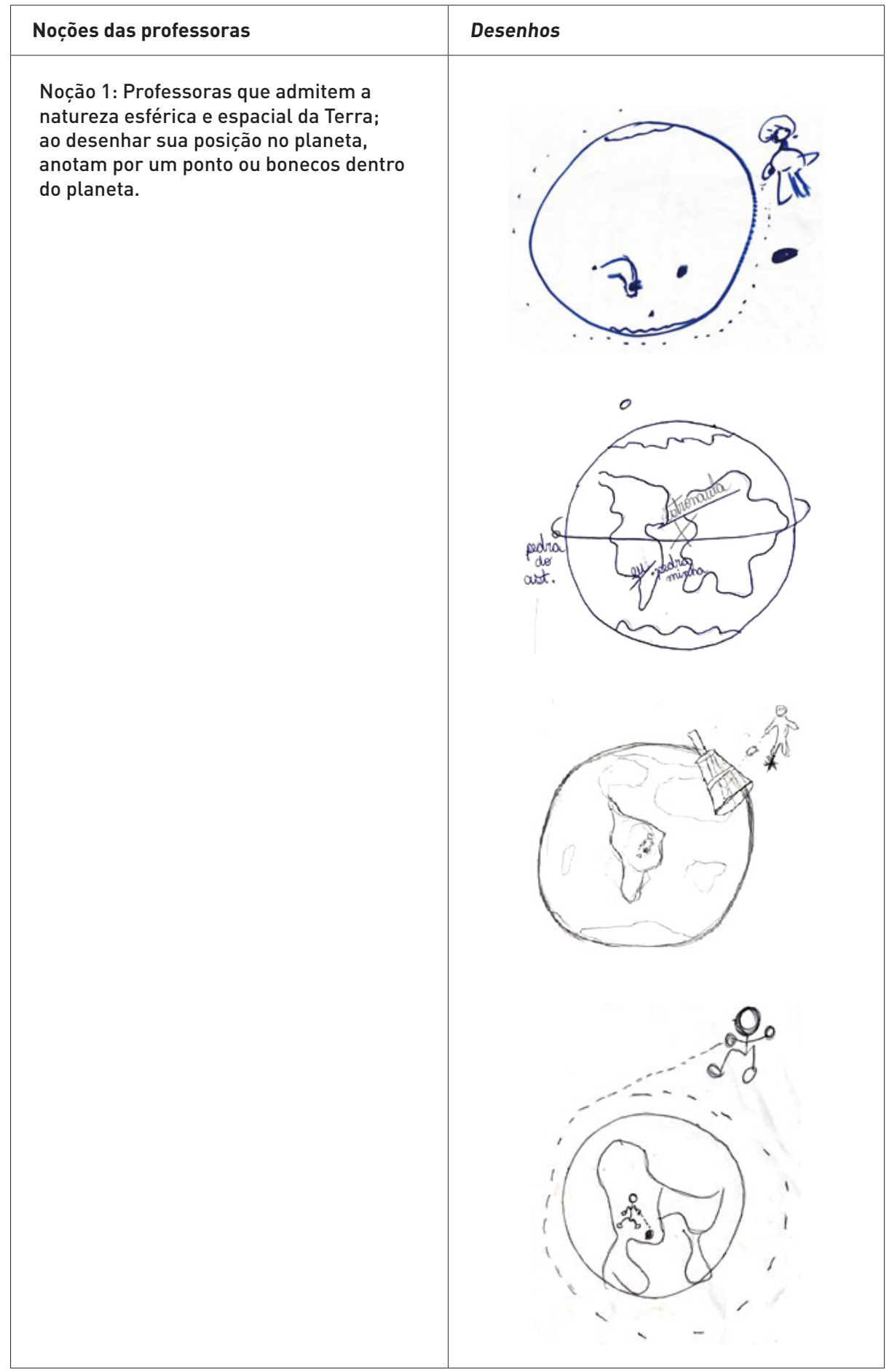


Noção 2: Concebem o formato do planeta Terra como esférico, porém, ao se localizarem no planeta, o desenho mostra uma parte inferior interna, o “chão". Os desenhos também apresentaram algumas variações, tais como a existência de alguns bonecos desenhados dentro do planeta, onde buscaram um apoio para os pés. Entende-se que os objetos dentro da Terra caem sempre para esse "chão” interno.
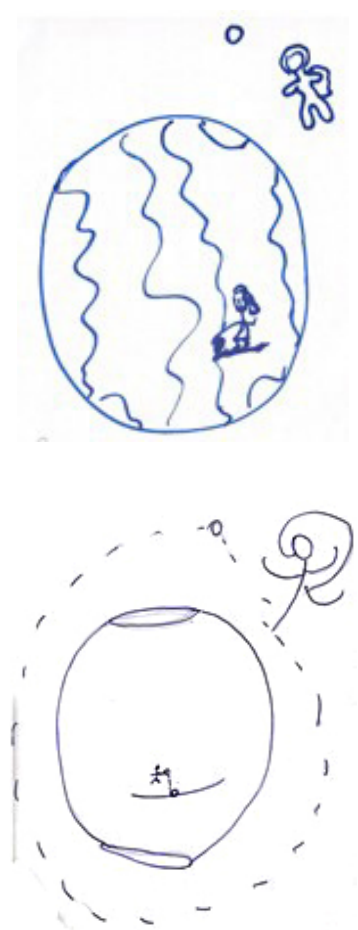

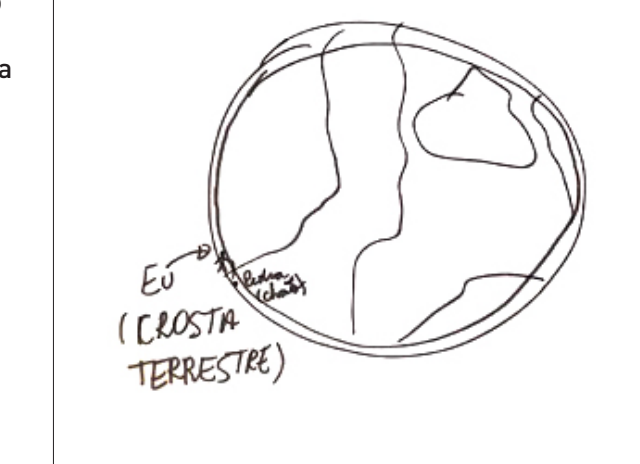

Noção 3: Consideraram que os corpos são atraídos na direção do centro da Terra. Algumas vezes apresentam um limite para a ação à distância. Tal limite, geralmente coincide com o fim da atmosfera.

Fonte: os autores, a partir dos dados da pesquisa.

Nessa perspectiva, Leite e Housume (2007, p.70) ressaltam:

A identificação de um número razoável de professores que ainda não possuem uma visão científica de Terra de algum modo mostra o quão forte é a representação do mundo da forma como o vemos, e o quão difícil é a extrapolação do vivencial para o científico, e também revela a ineficácia do livro didático e dos meios de comunicação em geral que, apesar de apresentarem uma Terra esférica, não fazem uma associação 
desta forma com a que observamos em nosso cotidiano. As Terras ocas, duplas e esféricas com vertical absoluta, mostram uma tentativa de correlação entre esses dois mundos: o vivencial e o científico.

Essa mesma constatação aparece na pesquisa de Ferreira e Leite (2015), na qual os autores indicam que a falta de transição entre as perspectivas de diferentes referenciais se constituiu em um dos obstáculos aos professores em relacionar a observação geocêntrica com a explicação heliocêntrica, ou a observação da Terra plana com o modelo de Terra esférica.

Entendemos que os desenhos elaborados pelas professoras remetem a seus imaginários, suas posições-sujeitos, pois, “[...] a imagem também informa, comunica, e sim porque - em sua especificidade - ela se constitui em texto, em discurso" (SOUZA, 1998, p.3).

O trabalho de interpretação da imagem, como na interpretação do verbal, vai pressupor também a relação com a cultura, o social, o histórico, com a formação social dos sujeitos. E vai revelar de que forma a relação imagem/interpretação vem sendo "administrada" em várias instâncias (SOUZA, 1998, p.4).

Nesse sentido, coadunamos com Palcha (2016), para quem a fala constitui um exercício de escolher as palavras e, a partir delas, nos expressarmos de uma forma, sobre um determinado sentido e não outro, não fugindo das expectativas do interlocutor. No entanto, há sempre "fuga de sentidos", escopos que tendem a mostrar que os sentidos podem ser outros, dependendo do contexto de interpretação. Nesse caso, as professoras, a partir de suas condições (circunstâncias da enunciação e memória) estão materializando sentidos ao "falarem" dos seus desenhos (ORLANDI, 2005).

Nessa perspectiva, podemos averiguar, diferentes movimentos de sentido no mesmo objeto simbólico (polissemia), neste caso, a mesma imagem (Figura 2). Segundo Elichirigoity (2017, p. 14) "uma forma-sujeito assim fragmentada devido à dispersão das posições-sujeito abre espaço, tanto para saberes de natureza semelhantes (o parafrástico e homogêneo) como para sentidos divergentes e contraditórios (o polissêmico e heterogêneo)".

A seguir, apresentamos discursos das professoras ao apresentarem seus respectivos desenhos quando questionadas sobre a forma do nosso planeta:

Luciana: Aqui está o meu planeta / não fiz uma esfera redondinha porque os polos são achatados/ então eu estou bem na crosta onde tem vida//

P: e por que no núcleo você não suportaria?

Luciana: por causa do calor! O núcleo é quente, a temperatura é alta, então eu estou na superfície, na crosta terrestre, onde tem vida!

Nesse discurso da Professora Luciana, percebe-se que ela se recorda de informações provavelmente relacionadas a conteúdos trabalhados na disciplina de Geografia. Podemos associar essa constatação (Terra achatada nos polos), conforme Leite e Housume (2007) categorizaram em seu artigo (percepção 
advinda da categoria livro didático), uma vez que esta informação é também bastante explicitada em livros didáticos de Ciências.

$\mathrm{Na}$ perspectiva da nossa pesquisa, segundo a Análise de Discurso, essa formação discursiva constitui-se em uma relação com o interdiscurso, o que significa que os saberes constituídos na memória do dizer do sujeito são históricos. Nessa lógica, o sujeito, ao mesmo tempo em que acredita ser a fonte exclusiva de seu discurso - ilusão subjetiva constitutiva do sujeito falante, seu dizer tem origem em outros discursos.

O próximo fragmento de discurso, da Professora Paula, explicita um detalhe diferente daqueles de outras professoras:

Paula: minha Terra é linda, rs... achatada nos polos e aqui estou eu jogando uma pedrinha/ coloquei aqui uma terrinha porque eu não podia estar voando e eu estou na superfície P: em que sentido você colocou essa "terrinha"?

Paula: no sentido de me apoiar, senão eu iria cair! Rs...

Figura 3. Desenho da professora Paula

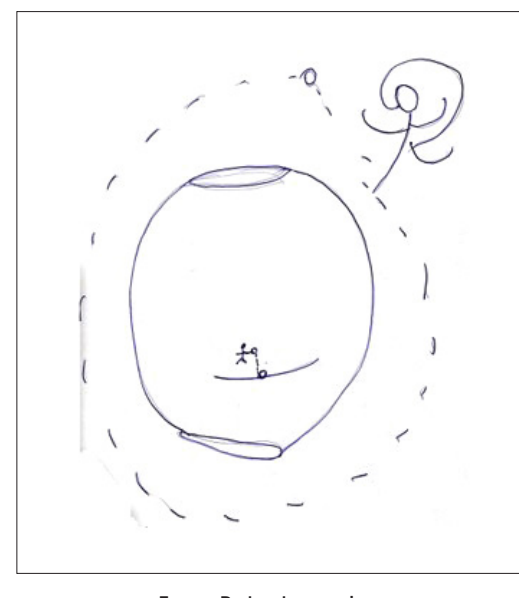

Fonte: Dados da pesquisa.

O desenho de Paula (Figura 3) é semelhante à categoria de "noção 3" explicitada por Nardi e Carvalho (1996), porém, em seu discurso, ela diz não considerar a Terra oca. Porém, considera que os objetos, dentro da Terra, caem sempre para esse "chão" interno.

Conforme a pesquisa de Ferreira e Leite (2015), percebemos uma contradição aparente entre seu desenho e o discurso e, no entanto, seus argumentos não explicaram o porquê dessa contradição ocorrer.

$\mathrm{Na}$ perspectiva da Análise de Discurso, o sujeito muitas vezes diz aquilo que espera que faça sentido para seu interlocutor, já restringindo sentidos possíveis. Acrescentamos que nesse jogo está a interpretação, ou a imagem do sujeito com relação ao seu interlocutor e ao objeto do discurso.

Nesse caso, a seguir, temos também o discurso e desenho (Figura 4) de Andressa: 
Andressa: Tentei fazer a Terra vista do espaço, tentei fazer ela no formato meio esférica por essa noção que Pitágoras deu pra ficar mais simples, mas ela é do tipo elipsoide, se não me engano/achatada nos polos!

Figura 4. Desenho elaborado pela Professora Andressa.

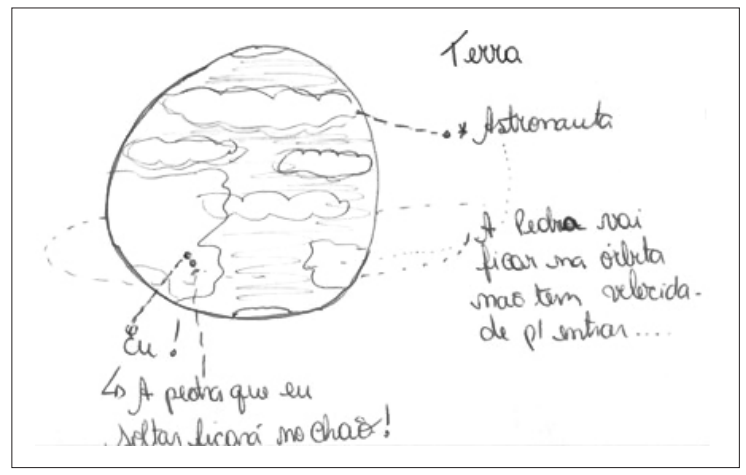

Fonte: Dados da pesquisa.

Assim, consideramos que, por meio do mecanismo de antecipação (AD), tentamos fazer com que os outros nos interpretem da maneira como gostaríamos. Já em conjunto com as relações de força, o mecanismo de antecipação pode nos levar a tentar dizer o que achamos que o outro quer ouvir (SILVA; ALMEIDA, 2018). Nesse sentido, comparando os desenhos elaborados pelas professoras e seus respectivos discursos, percebe-se evidências desse tipo de imaginário.

A seguir, apresentamos trechos de discursos que reforçam essa interpretação e destacam a compreensão do conceito de gravidade diferente da aceita cientificamente, conforme apresentado no Quadro 4.

P: Foi solicitado que vocês imaginassem que o astronauta estaria com uma pedra em mãos/ e aí ele abandonaria essa pedra//vamos ver alguns desenhos//aliás vamos ver a ideia da Deise e quem teve a ideia, o pensamento parecido com o da Deise, levante a mão! Deise: então... eu desenhei o astronauta soltando a pedra//

P: e pra onde foi a pedra?

Deise: aqui/ [aponta para o desenho] eu imaginei a pedra como se fosse um meteoro/ meteorito/ que ela iria entrar na Terra e ia caindo//

P: então a ideia da Deise é que a pedra cairia no planeta Terra, quem concorda?

Abadia: eu concordo/ porque a minha também caiu no mar! rs...

P: então só as duas pensaram iguais?

Kelly: a minha ficou flutuando no espaço!

P: a pedra seguiu alguma trajetória Kelly?

Kelly: não... ficou vagando ali, perambulando...

P: longe do astronauta?

Kelly: é!

Andressa: a minha pedra o astronauta jogou e ela ficou ali / que nem ele/na mesma órbita da Terra, porque ele tá sendo atraído por ela!

P: ele tá sendo atraído pelo quê? 
Andressa: pela gravidade da Terra! e ela não entrou na atmosfera porque ela não tem a velocidade para entrar na Terra...

P: gente, então, nós tivemos três explicações diferentes da trajetória da pedra do astronauta!

Quadro 4. Formaç̃oes imaginárias das professoras sobre a gravidade

(Se 0 astronauta da Figura 2 abandonasse uma pedra, para onde ela iria?)

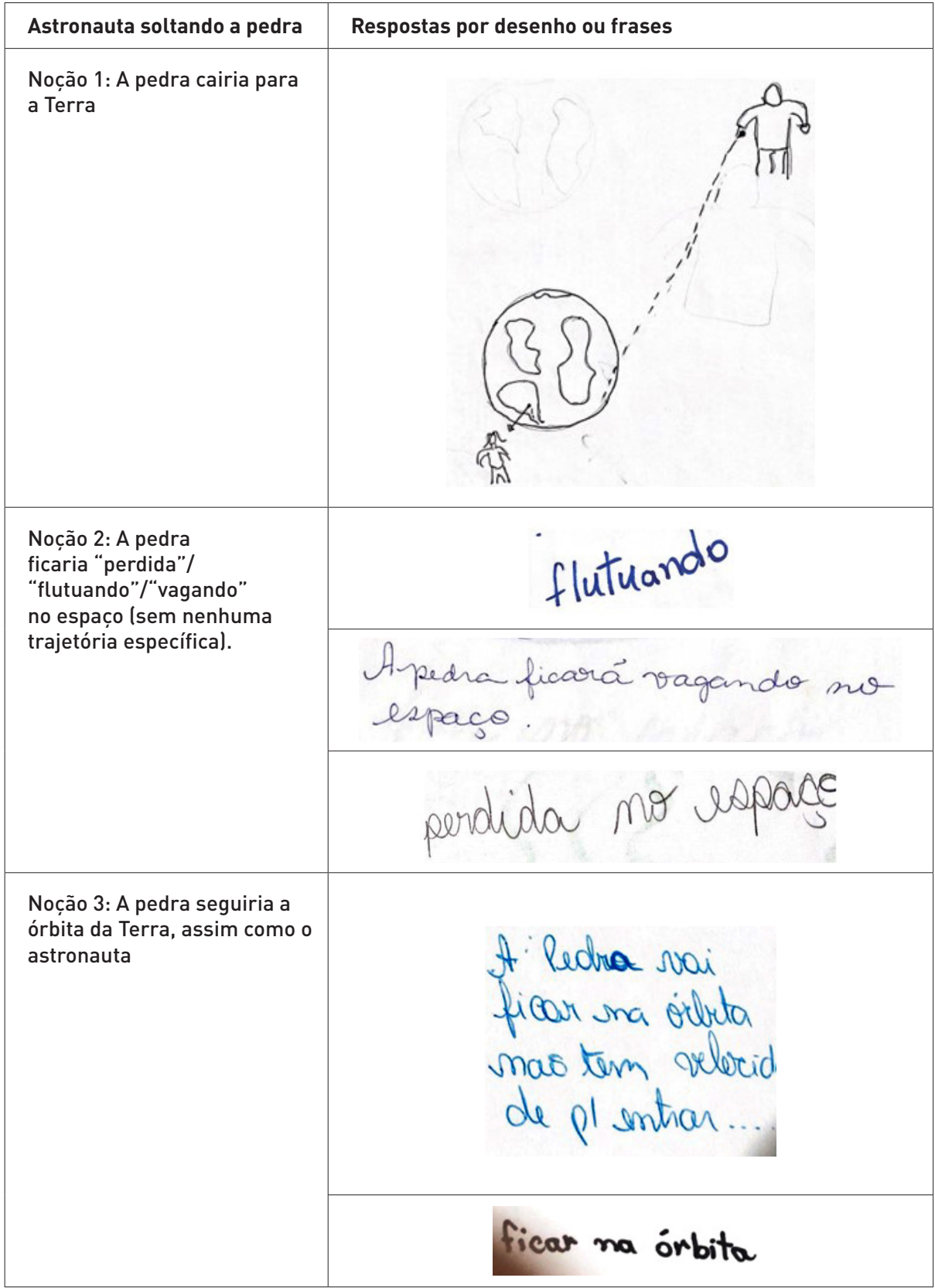

Fonte: 0 s autores, a partir dos dados da pesquisa. 
Nos trechos a seguir, a pesquisadora questiona as professoras por que o astronauta não cai na Terra:

P: Por que esse astronauta (aponta para a figura) não cai na Terra?

Andressa: por causa da gravidade!

P: Por causa da gravidade do quê?

Rute: A força da gravidade ... a força da gravidade da Terra

P: a força da gravidade da Terra?

Abadia: acho que é do espaço

P: o espaço cria a gravidade?

Abadia: aham...

Andressa: a Terra tem uma órbita e essa órbita da Terra vai atraí-lo...

P: então por isso ele não cai?

Deise: isso!

Neste caso, podemos interpretar duas formações imaginárias presentes nos discursos das professoras: que o astronauta não cai por causa da força da gravidade da Terra ou da força da gravidade do espaço.

Percebemos aí um retorno ao mesmo espaço dizível (paráfrase), porém, com variedade da situação, no discurso de Andressa. A primeira situação: "a minha pedra o astronauta jogon e ela ficou ali / que nem ele/ na mesma órbita da Terra, porque ele tá sendo atraído por ela! A segunda situação: a Terra tem uma órbita e essa órbita da Terra vai atrai-lo...(astronauta).

Podemos dizer que a formação imaginária de Andressa sobre a gravidade foi a mais próxima do conhecimento aceito cientificamente. Nesse sentido, a paráfrase foi um elemento da Análise de Discurso que nos auxiliou constatar deslizamentos nos sentidos explicitados pelas professoras.

\section{CONSIDERACִÕES FINAIS}

Neste artigo, buscamos trazer contribuições à pesquisa sobre formação de professores mostrando percepções (formações imaginárias) sobre os temas "forma da Terra" e o conceito de gravidade.

Merece destacar o fato de este projeto de formação continuada sobre o ensino de física ter ocorrido na escola, em serviço, com assessoria contínua de pesquisadores da Universidade. Isto foi imprescindível para avaliar a mudança de postura dos participantes do curso, por meio da interpretação dos discursos das professoras participantes do projeto.

Os sujeitos dessa pesquisa, professoras, em sua maioria pedagogas, estão falando de uma posição, de um lugar social determinado: o de docentes que também ministram ciências nos anos iniciais do ensino fundamental da rede pública de uma cidade média (cerca de 50.000 habitantes) do interior do estado de Minas Gerais.

$\mathrm{O}$ fato de a pesquisadora que as assessorou diretamente ter sido aluna da escola e o estabelecimento de um clima de cooperação com a direção da escola e o grupo de professoras, desde as discussões para início do projeto, foram importantes. Soma-se ao fato de a pesquisadora ter garantido sigilo sobre as 
informações e ter planejado o curso em conjunto com a coordenação pedagógica e as docentes que, desde o início, apontaram os pontos do currículo que tinham insegurança em trabalhar com seus alunos.

Isso foi significativo, uma vez que a pesquisadora teve a confiança das docentes, ou seja, sua imagem de uma colega professora mais experiente atenuou a de um investigador de uma universidade. Ou seja, um pesquisador externo, falando de uma posição imaginária superior, e que estaria avaliando as professoras, ao coletar informações de pesquisa, entre docentes dos anos iniciais do ensino fundamental.

Com relação especificamente aos conteúdos de ensino trabalhados na atividade considerada neste artigo: a "forma da Terra" e o conceito de gravidade, foi possível compreender como o discurso científico é recontextualizado em diferentes estratégias metodológicas. Foi possível ainda, não só nesta, como nas demais atividades do curso, não apenas apresentar e discutir resultados de pesquisa, mas também levar as professoras e testá-los em sala de aula e refletir coletivamente sobre os resultados obtidos, socializando os problemas e/ou êxitos.

$\mathrm{Na}$ elaboração dos desenhos sobre a forma da Terra e a localização dos sujeitos, tarefa que, a princípio, mostrava-se simples de analisar, na verdade tornou-se mais complexa, quando observou-se a polissemia de sentidos sobre o mesmo objeto simbólico. Podemos afirmar que houve aí, em alguns momentos, indícios de "fugas de sentido" (ORLANDI, 2005). Neste caso, emergiram nas explicações sentidosalternativos, que foram incoerentes com os desenhos elaborados, evidenciando relações ditas e não-ditas. Dessa forma, o desenvolvimento desse tipo de atividades permitiu que as professoras tomassem consciência de suas concepções e percebessem a necessidade de incorporar novos sentidos e estratégias no ensino sobre o tema.

Este estudo ratifica, de certa forma, resultados da pesquisa de Leite e Housume (2007. p.70), já citados anteriormente, uma vez que mostra “... quão forte é a representação do mundo da forma como o vemos, e o quão difícil é a extrapolação do vivencial para o científico". Constatamos também que as docentes deste estudo, “... apesar de apresentarem uma Terra esférica, não fazem uma associação desta forma com a que observamos em nosso cotidiano".

$\mathrm{O}$ intuito de contribuir para a atualização de docentes dos anos iniciais de ensino fundamental, mostra-se importante, uma vez que, ao diminuir a distância entra a universidade e a educação básica, objetivo do projeto, os pesquisadores conseguiram diminuir a distância entre a pesquisa e a sala de aula.

Entendemos que quanto mais previamente começarmos a discutir a forma do Planeta Terra, nossa localização e nosso posicionamento em relação a sua superfície, provavelmente o aprendizado destas questões será mais facilitado para os alunos em níveis mais elevados de escolarização, o que está de acordo com Agan e Sneider (apud BARBOSA-LIMA, 2010). E porque viram neste curso, em serviço, um diferencial em relação a outros que ocorrem no âmbito da Universidade, muitas vezes desconsiderando os contextos onde os docentes atuam.

Por fim, entendemos que esta forma de cooperação, que ocorre em serviço, mostrou-se como inovação para os professores que atuaram no projeto e a esta deverá se ampliar para outras áreas, conforme solicitação dos docentes envolvidos e da direção desta unidade escolar. 


\section{AGRADECIMENTOS}

Os autores agradecem respectivamente ao Instituto de Física da Universidade Federal de Uberlândia (UFU), pela licença concedida para o primeiro autor desenvolver a pesquisa e ao CNPq - Conselho Nacional de Desenvolvimento Científico e Tecnológico - Processo 405.487/2018-5 - (segundo autor) pelo financiamento parcial da pesquisa que gerou este artigo. Agradecem particularmente a direção, coordenação pedagógica, funcionários e os docentes que fizeram parte do projeto de pesquisa, cujos dados foram essenciais para possibilitar esta publicação.

\section{REFERÊNCIAS}

BARBOSA-LIMA, M. C. Conversando com Lara sobre a terra e a Terra. RELEA, Revista LatinoAmericana de Educação em Astronomia, 10, p. 23-35, 2010.

BARROS, T. H. B. Uma trajetória da Arquivística a partir da análise do discurso: inflexões histórico-conceituais. São Paulo: Editora da Unesp, 2015.

CARVALHO, A. M. P. Critérios estruturantes para o ensino das ciências. CARVALHO, A. M. P. (org.), Ensino de ciências: unindo a pesquisa e a prática. São Paulo: Pioneira Thomson Learning, p. 1-18, 2015.

CASTILHO, A. T.; PRETI, D. A linguagem falada culta na cidade de São Paulo: materiais para o seu estudo. v. II: Diálogos entre dois informantes. São Paulo: T. A. Queiroz: FAPESP, 1986.

CUNHA, R. C. O. B.; PRADO, G. V. T. Formação centrada na escola, desenvolvimento pessoal e profissional de professores. Revista Educação PUC-Campinas, Campinas, n.28, p. 103-113, 2010.

ELICHIRIGOITY, M. T. P. Análise do discurso na área de letras. CadIl -Cadernos do Instituto de Letras, Porto Alegre, v. 1, n. 34, p. 169-199, 2017.

FERREIRA, F. P; LEITE, C. A forma e os movimentos da terra: percepções de professores acerca das relações entre observação cotidiana e os modelos científicos. RELEA- Revista Latino-Americana de Educação em Astronomia, n. 19, p. 123-146, 2015

GIRALDI, L. P. B. Os níveis diferenciados de desempenho escolar: analisando estabilidade e mudanças nas concepções e expectativas de professores, familiares e alunos. 2010. Dissertação (Mestrado em Educação Escolar). Universidade Estadual Paulista "Júlio de Mesquita Filho", Araraquara, 2010.

GONZÁLES-REY, F. LA pesquisa e o tema da subjetividade em educação. Psicologia da Educação - Revista do Programa de Estudos Pós-Graduados, São Paulo, n. 13, p. 9-15, 2001. Disponível em:https://revistas.pucsp.br/psicoeduca/article/view/32815/22634. Acesso em: 03 jul. 2020.

LANG, F. Sobre a forma da Terra. Revista Física na Escola, v. 15 n. 2, p. 4 - 14. 2017.

LEITE, C.; HOSOUME, Y. Os professores de Ciências e suas formas de pensar a astronomia. RELEA, Revista Latino-Americana de Educação em Astronomia -, n. 4, p. 47-68, 2007 
LIMA, S. C. Um estudo sobre o desenvolvimento profissional de professores dos anos iniciais do ensino fundamental, embasado na inserção de conteúdos de Física no Ensino de Ciências e na produção acadêmica da área, como elementos inovadores, sob a assessoria de uma Universidade. Tese (Doutorado em Educação para a Ciência). Universidade Estadual Paulista. Faculdade de Ciências, Bauru, 2018, 213p.

NARDI, R.; BASTOS, GATTI, S. R. T.; CORTELA, B. S. C.; LANGHI, R.; TERRAZZAN, E. A.; MIANUTTI, J. O diálogo entre a produção acadêmica em Ensino de Ciências e os saberes e práticas docentes em diferentes níveis de ensino e espaços educativos. Bauru: UNESP, Faculdade de Ciências, 2016. 54p. (Relatório científico referente a projeto de pesquisa financiado através do Edital CNPq no 14/2013).

NARDI, R.; CARVALHO, A. M. P. Um estudo sobre a evolução das noções de estudantes sobre espaço, forma e força gravitacional do planeta terra. Investigações em Ensino de Ciências, Porto Alegre, v. 1, n. 2, p. 132-144, 1996.

ORLANDI, E. P. Interpretação. Petrópolis: Vozes. 1996.

ORLANDI, E. P. Identidade linguística escolar. In: SIGNORINI. I. (org.). Lingua(gem) e identidade. Campinas: Mercado de Letras. 1998. p. 203-212.

ORLANDI, E. P. O campo da análise de discurso no Brasil: mapeando conceitos, confrontando limites. In: II SEAD - Seminário de Estudos em Análise do DiscursoPortoAlegre, 2005. Anais... Porto Alegre: UFRGS, 2005, p. 1-18 Disponível em: http://www.ufrgs.br/analisedodiscurso/ anaisdosead/1SEAD/Conferencias/EniOrlandi.pdf. Acesso em: 03 jul. 2020.

ORLANDI, E. P. Discurso e texto. Campinas: Pontes. 2008.

ORLANDI, E. P. Análise de discurso: princípios \& procedimentos. $8^{\mathrm{a}}$ ed. Campinas: Pontes. 2009.

ORLANDI, E. P. Análise de discurso: princípios e procedimentos. 11ª ed. Campinas: Pontes. 2013.

PALCHA, L. S. O efeito-leitor na mediação de conhecimentos do estágio: uma análise dos discursos de Licenciandos em Ciências Biológicas. 2016. Tese (Doutorado em Educação). Programa de Pós-Graduação em Educação da Universidade Federal do Paraná, Curitiba, 2016.

PÊCHEUX, M. O discurso: estrutura ou acontecimento. Campinas: Pontes. 1990.

PÊCHEUX, M. Semântica e discurso: uma crítica à afirmação do óbvio. Campinas: Editora da Unicamp. 1997.

PINTO, S. P.; FONSECA, O. M.; VIANNA, D. M. Formação continuada de professores: estratégias para o ensino de astronomia nas séries iniciais. Cadernos Brasileiro de Ensino de Física, v. 24, n. 1, p. 71-86, 2007.

SANTOS, M. E. M. Era uma vez a Análise do Discurso sobre as princesas dos contos de fada em animações da Walt Disney. CadIl -Cadernos do Instituto de Letras, Porto Alegre, n. 1, p. 361 380. 2016.

SILVA, A. C.; ALMEIDA, M. J. P. M. Estratégias para a coleta de informações numa pesquisa com apoio teórico-metodológico na análise de discurso. Revista Brasileira de Pesquisa em Educação em Ciências, v. 17, n. 3, p. 883-902, 2017 
SOUZA, T. C. C. de. Discurso e imagem: perspectivas de análise do não verbal. C-legenda Revista do Programa de Pós-graduação em Cinema e Audiovisual da Universidade Federal Fluminense, n. 1, p. 1-10, 1998.

VILLANI, C. E. P. As práticas discursivas argumentativas de alunos do ensino médio no laboratório didático de Física. 2002. 188f. Dissertação (Mestrado em Educação) - Universidade Federal de Minas Gerais, Belo Horizonte, 2002.

\section{NOTAS}

1 https://srefabricianodivep.files.wordpress.com/2017/02/cbc-anos-iniciais.pdf.

Submetido em 27/02/2020

Aprovado em 01/08/2020

\section{Contato:}

Sorandra Corrêa de Lima

Universidade Federal de Uberlândia

Campus Monte Carmelo

KM 1, LMG-746

CEP 38.500-000 - Monte Carmelo, MG - Brasil 